\title{
Transitions between Different Scaling Modes in the Oxidation of $\mathrm{Cu}-\mathrm{Al}$ Alloys
}

\author{
F. Gao and Y. Niu ${ }^{\circ}$ \\ State Key Laboratory for Corrosion and Protection, Institute of Metal Research, \\ Chinese Academy of Sciences, Wencui Rd 62, 110016 Shenyang (China)
}

(Received October 31, 2006: final form November 6, 2006)

\begin{abstract}
The oxidation of binary $\mathrm{Cu}-\mathrm{Al}$ alloys containing 1.4, $2.2,3.0,4.2$ and 6.5 at. $\% \mathrm{Al}$ was studied at $1073 \mathrm{~K}$ in 0.1 $\mathrm{MPa} \mathrm{O}_{2}$. The increase of the $\mathrm{Al}$ content produced first a transition from internal oxidation of aluminum to the growth of mixed $\mathrm{Cu}+\mathrm{Al}$ external oxide scales and later on to the formation of external $\mathrm{Al}_{2} \mathrm{O}_{3}$ scales. The critical Al contents required for the transitions between different oxidation modes are predicted and compared with the experimental results.
\end{abstract}

Keywords: $\mathrm{Cu}-\mathrm{Al}$ alloys, Oxidation, Transition, Alumina

\section{INTRODUCTION}

According to the results of previous investigations $/ 1-8 /$, aluminum additions to copper can greatly improve its oxidation resistance at high temperatures, especially by forming continuous and compact $\mathrm{Al}_{2} \mathrm{O}_{3}$ films. However, relatively limited detailed information is available concerning the critical $\mathrm{Al}$ contents needed to avoid the internal oxidation of aluminum and to form protective external $\mathrm{Al}_{2} \mathrm{O}_{3}$ scales on $\mathrm{Cu}-\mathrm{Al}$ alloys. In particular, the critical Al level for ideal oxidation resistance in high oxygen pressures has been reported to fall inside a large range, extending from about 8.9 to 20 at.\% /1,4,6/. However, these conclusions are not only in disagreement but also questionable because they were sometimes based only on measurements of mass gains after a fixed time, which may be strongly affected by the existence of a faster initial stage, rather than on the steady-state corrosion rates and in some cases without any direct observation of cross sections. In fact, when the content of the more reactive component of binary alloys is only slightly above the value sufficient to form an external scale of its oxide, they may still form initially consistent amounts of the less stable oxide before producing a continuous layer of the more stable compound. This situation involves rather large initial mass gains if, as in the present case, the less stable oxide grows much more rapidly than the oxide of the more reactive alloy component. However, in this case the oxidation rate decreases very sharply after forming a continuous layer of the protective oxide at the base of the scale, resulting eventually in a protective behavior. In addition, the criterion commonly adopted in some old papers to estimate the ability of a binary alloy to form protective scales composed of the most stable oxide was apparently based on the total absence of the less stable oxide in the scales, even if formed only during an initial transient stage. This condition is considered too restrictive and is replaced by the assessment of the ability of an alloy to form a continuous layer of the most stable oxide over its surface after the initial stage, as evidenced by a coupled analysis of the scale microstructure and the oxidation kinetics.

In this paper, five binary $\mathrm{Cu}-\mathrm{Al}$ alloys with $\mathrm{Al}$ contents ranging approximately from 1 to 7 at.\% have been oxidized at $1073 \mathrm{~K}$ in $0.1 \mathrm{MPa} \mathrm{O}_{2}$ to examine in more detail the conditions for the transitions between their possible oxidation modes, including the internal 
oxidation of aluminum and the formation of external protective $\mathrm{Al}_{2} \mathrm{O}_{3}$ scales.

\section{EXPERIMENTAL}

Five binary $\mathrm{Cu}-\mathrm{xAl}$ alloys $(\mathrm{x}=1.4,2.2,3.0,4.2$ and 6.5 at.\%, determined by means of Electron Microprobe Analysis) were melted under vacuum using high purity metals. After annealing in argon at $1173 \mathrm{~K}$ for $48 \mathrm{~h}$, specimens with $12 \times 8 \times 1.2 \mathrm{~mm}^{3}$ size were cut with a diamond-wheel saw. After being mechanically abraded on successively finer $\mathrm{SiC}$ papers down to 2500 grit, all the samples were cleaned ultrasonically with ethanol and acetone and then dried immediately before each test. All the alloys were oxidized in $0.1 \mathrm{MPa}$ of pure $\mathrm{O}_{2}$ at $1073 \mathrm{~K}$ for $24 \mathrm{~h}$ with continuous mass-gain measurement using a Cahn-2000 thermobalance. X-ray diffraction (XRD), Scanning electron microscopy (SEM) and an energy-dispersive $\mathrm{X}$-ray microanalysis system (EDX) were used to establish the nature, composition and spatial distribution of the compounds formed during oxidation.

\section{RESULTS}

\subsection{Oxidation kinetics}

The kinetic curves of the five $\mathrm{Cu}-\mathrm{Al}$ alloys oxidized at $1073 \mathrm{~K}$ in $0.1 \mathrm{MPa}$ of pure $\mathrm{O}_{2}$ are shown in Fig.la as normal plots and in Fig. $\mathrm{lb}$ as parabolic plots. The kinetic curve of $\mathrm{Cu}-1.4 \mathrm{Al}$ was approximately parabolic over the whole oxidation period with an average parabolic rate constant $k_{p}$ equal to $1.3 \mathrm{~g}^{2} \mathrm{~m}^{-4} \mathrm{~s}^{-1}$. The three alloys $\mathrm{Cu}-2.2 \mathrm{Al}, \mathrm{Cu}-4.2 \mathrm{Al}$ and $\mathrm{Cu}-6.5 \mathrm{Al}$ had instantaneous parabolic rate constants (slopes of the parabolic plots) decreasing with time during an initial period of different duration (about $2.2 \mathrm{~h}, 0.5 \mathrm{~h}$ and $1.6 \mathrm{~h}$ for $\mathrm{Cu}-2.2 \mathrm{Al}, \mathrm{Cu}-4.2 \mathrm{Al}$ and $\mathrm{Cu}-6.5 \mathrm{Al}$, respectively) before reaching a steady-state condition with parabolic rate constants equal to $6.9 \times 10^{-1} \mathrm{~g}^{2} \mathrm{~m}^{-4} \mathrm{~s}^{-1}$ for $\mathrm{Cu}-2.2 \mathrm{Al}$ and $5.5 \times 10^{-5} \mathrm{~g}^{2} \mathrm{~m}^{-4} \mathrm{~s}^{-1}$ for both $\mathrm{Cu}-4.2 \mathrm{Al}$ and $\mathrm{Cu}-6.5 \mathrm{Al}$, respectively. Finally, $\mathrm{Cu}-3.0 \mathrm{Al}$ had two parabolic stages with rate constants equal to $1.2 \mathrm{~g}^{2} \mathrm{~m}^{-4} \mathrm{~s}^{-1}$ (from 0 to $1.3 \mathrm{~h}$ ) and $1.4 \times 10^{-1} \mathrm{~g}^{2} \mathrm{~m}^{-4} \mathrm{~s}^{-1}$ (from 6.9 to $24 \mathrm{~h}$ ) connected by an intermediate stage with an instantaneous parabolic rate constant decreasing continuously with time.

\subsection{Scale morphology and composition}

The microstructures of the scales formed on the $\mathrm{Cu}$ $\mathrm{xAl}$ alloys after $24 \mathrm{~h}$ oxidation at $1073 \mathrm{~K}$ in $0.1 \mathrm{MPa}$ of pure $\mathrm{O}_{2}$ are shown in Figs. 2-4. The $\mathrm{Cu}-1.4 \mathrm{Al}$ alloy (Fig. 2) formed external scales composed of an outermost thin layer of $\mathrm{CuO}$ and a much thicker inner $\mathrm{Cu}_{2} \mathrm{O}$ layer containing some aluminum, mostly in the alloy-consumption zone. Moreover, $\mathrm{Cu}-1.4 \mathrm{Al}$ formed also a rather thick zone of internal oxidation of aluminum, rather difficult to observe due to the very small size of the internal oxide particles, so that the location of the internal oxidation front (IOF) is only revealed by a shade of gray slightly darker than the bulk alloy, as marked in Figs. 2a-2b. Cu-2.2Al formed similar external scales (Fig. 3a), while the zone of internal oxidation was very thin and presented an unusual structure (Fig. 3b), since $\mathrm{Al}_{2} \mathrm{O}_{3}$ did not form small particles uniformly distributed in the $\mathrm{Cu}$ matrix, but rather a number of thin bands approximately parallel to the alloy surface. Moreover, the internal oxidation zone was only present over a fraction of the alloy surface, so that this alloy appears borderline between internal and external oxidation of aluminum. The internal oxidation was completely absent in the case of Cu-3.0Al (Fig. 4a), which formed scales of irregular thickness, similar to those grown on the more dilute alloys, composed of a very thin outermost $\mathrm{CuO}$ layer overlying a thick $\mathrm{Cu}_{2} \mathrm{O}$ matrix which in its inner region contained alumina, mostly distributed along curved bands, roughly parallel to the alloy surface, sometimes also present directly at the alloy/scale interface. Finally, both $\mathrm{Cu}-4.2 \mathrm{Al}$ and $\mathrm{Cu}-6.5 \mathrm{Al}$ (Figs. $4 \mathrm{~b}$ and $4 \mathrm{c}$ ) were able to form continuous alumina layers in contact with the alloy, surmounted in both cases by an external $\mathrm{CuO}$ layer formed during the initial period of faster oxidation, much thicker for $\mathrm{Cu}-4.2 \mathrm{Al}$ (about $30 \mu \mathrm{m}$ ) than for $\mathrm{Cu}-6.5 \mathrm{Al}$ (about $3 \mu \mathrm{m}$ ).

\section{DISCUSSION}

In principle, the high temperature oxidation of binary A-B alloys, where $\mathrm{A}$ is the more noble and $\mathrm{B}$ the 

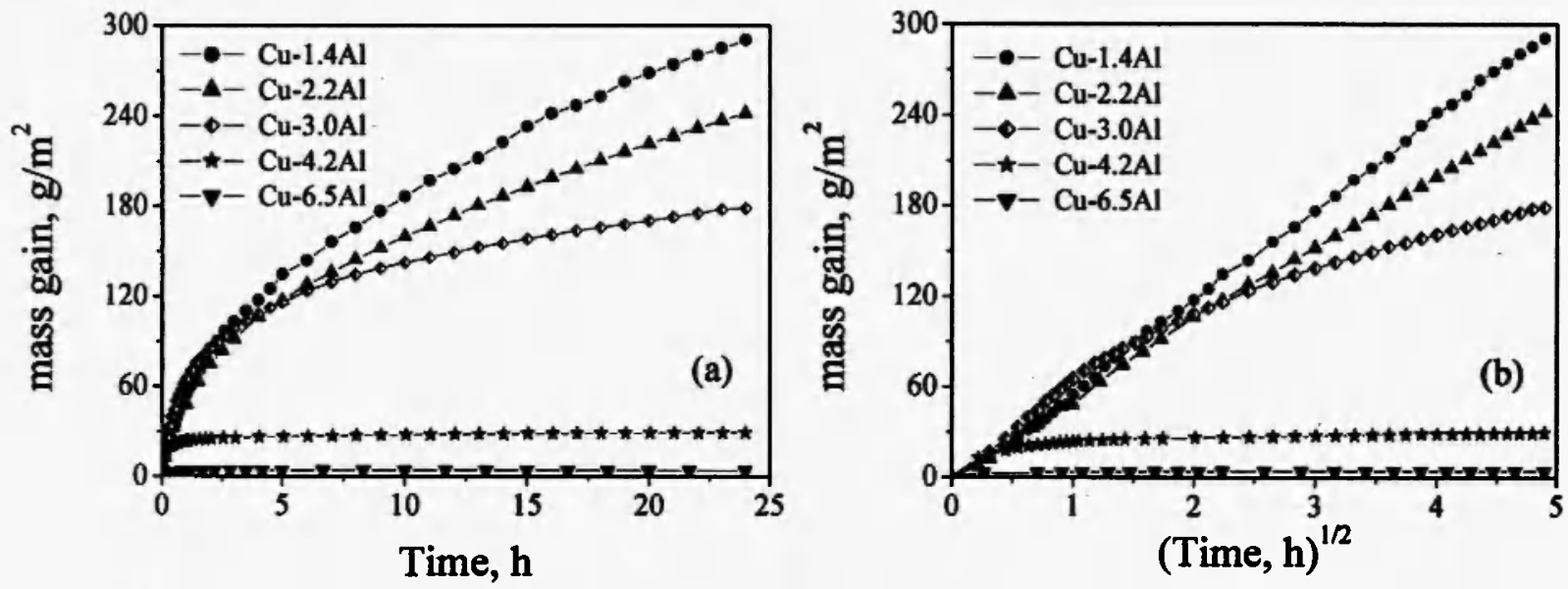

Fig. 1: Oxidation kinetics of five Cu-xAl $(x=1.4,2.2,3.0,4.2,6.5$ at.\%) alloys oxidized for $24 \mathrm{~h}$ at $1073 \mathrm{~K}$ in $0.1 \mathrm{MPa}$ $\mathrm{O}_{2}$ : (1a) Normal plot; (1b) Parabolic plot.
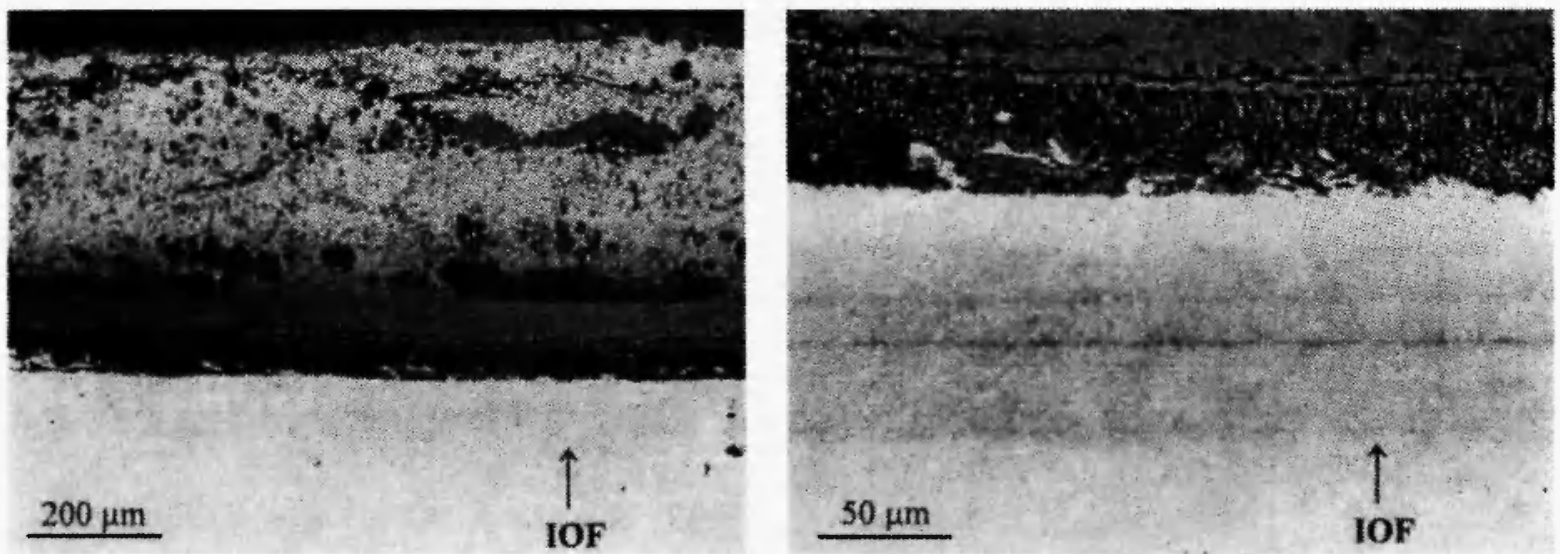

Fig. 2: Micrographs (SEM/BEI) of a cross section of Cu-1.4Al oxidized for $24 \mathrm{~h}$ in $0.1 \mathrm{MPa} \mathrm{O}_{2}$ at $1073 \mathrm{~K}$ : (2a) General view; (2b) Expanded view of the internal oxidation zone.
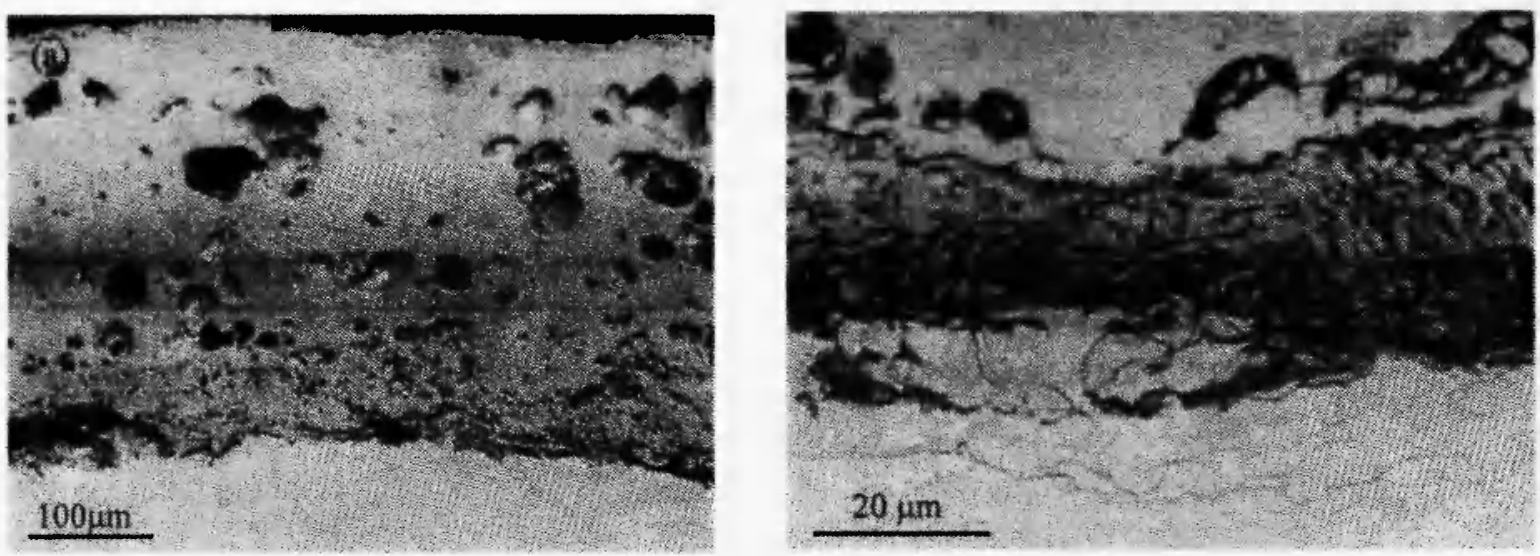

Fig. 3: Micrographs (SEM/BEI) of a cross section of $\mathrm{Cu}-2.2 \mathrm{Al}$ oxidized for $24 \mathrm{~h}$ in $0.1 \mathrm{MPa} \mathrm{O}_{2}$ at $1073 \mathrm{~K}$ : 3a) General view; (3b) Expanded view of the internal oxidation zone. 

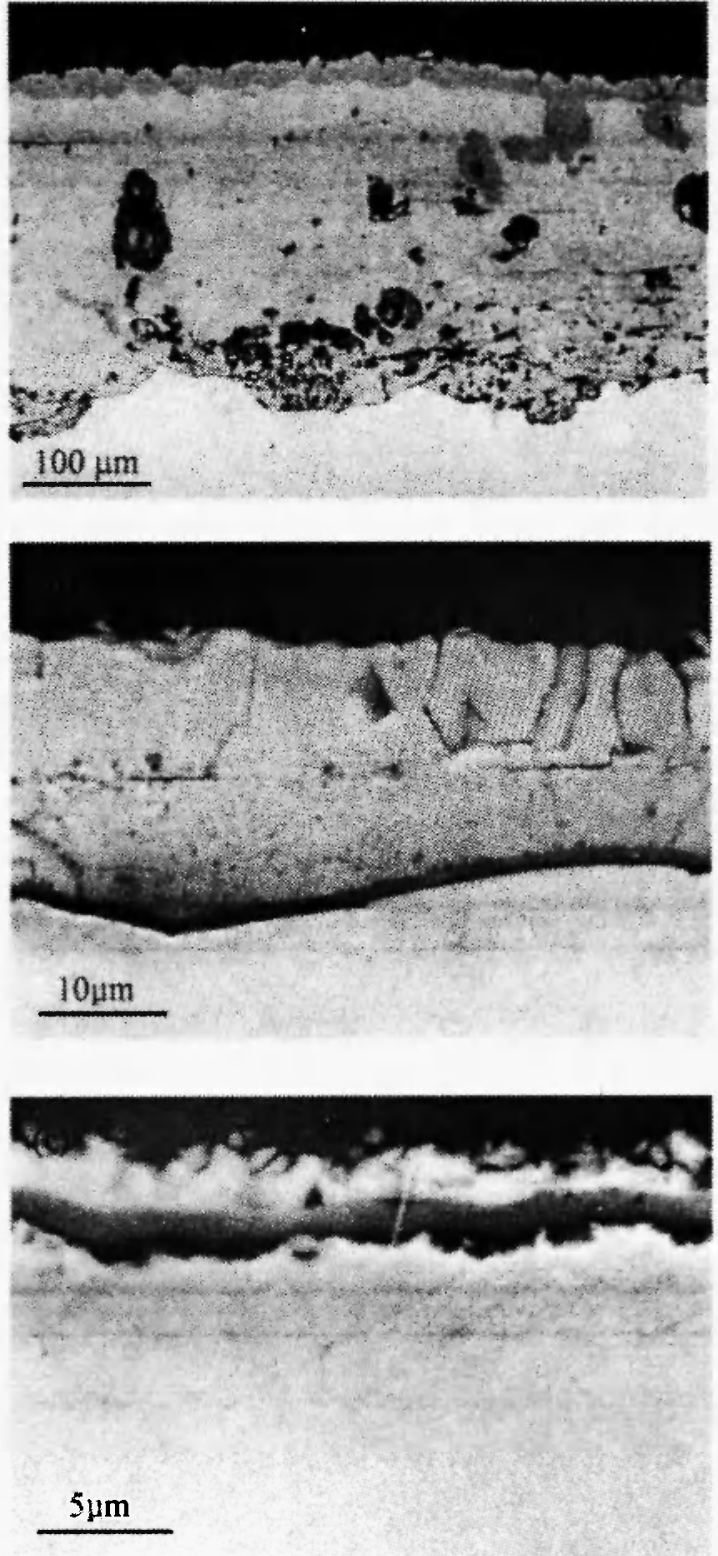

Fig. 4: Micrographs (SEM/BEI) of cross sections of $\mathrm{Cu}-3.0 \mathrm{Al}$ (4a), Cu-4.2Al (4b) and $\mathrm{Cu}-6.5 \mathrm{Al}$ (4c) oxidized for $24 \mathrm{~h}$ in $0.1 \mathrm{MPa} \mathrm{O}_{2}$ at $1073 \mathrm{~K}$

more reactive component, under oxidant pressures above the stability of the less stable oxide can result in three main oxidation modes (om). Assuming the formation of oxides $\mathrm{AO}$ and $\mathrm{BO}_{v}$, these include 1) the growth of external $\mathrm{AO}$ scales coupled with an internal oxidation of $\mathrm{B}$, consisting in the precipitation of isolated $\mathrm{BO}_{v}$ particles inside a matrix of pure $\left.\mathrm{A}(\mathrm{om} 1), 2\right)$ the growth of external scales composed of mixtures of $\mathrm{AO}$
$+\mathrm{BO}_{\mathrm{v}}(\mathrm{om} 2)$ and 3 ) the exclusive growth of external $\mathrm{BO}_{v}$ scales (om3) /9-11/. However, not all of the binary alloys may actually form all these three different types of scales. In fact, the first oxidation mode is only stable below a first critical $B$ content, $\mathrm{N}_{\mathrm{B}}{ }^{\circ}(1)$, while the third oxidation mode is only stable above a second critical $\mathrm{B}$ content, $\mathrm{N}_{\mathrm{B}}{ }^{0 *}(2)$. Therefore, if $\mathrm{N}_{\mathrm{B}}{ }^{0 *}(1)<\mathrm{N}_{\mathrm{B}}{ }^{\circ *}(2)$, an increase of the bulk $B$ content, $\mathrm{N}_{\mathrm{B}}{ }^{\circ}$, will produce first a transition from om1 to om2 (transition 1-2) at $\mathrm{N}_{\mathrm{B}}{ }^{\circ}=$ $\mathrm{N}_{\mathrm{B}}{ }^{\circ}$ (1) and later on a second transition from om2 to om3 (transition 2-3) at $\mathrm{N}_{\mathrm{B}}{ }^{0}=\mathrm{N}_{\mathrm{B}}{ }^{\circ} *(2)$. Conversely, if $\mathrm{N}_{\mathrm{B}}{ }^{0} *(1)>\mathrm{N}_{\mathrm{B}}{ }^{0 *}(2)$, there will be only a transition from om1 to om3 (transition 1-3) at $\mathrm{N}_{\mathrm{B}}{ }^{0}=\mathrm{N}_{\mathrm{B}}{ }^{0}$ (1) /11/. In fact, in this case the second oxidation mode is forbidden because it is only stable in a range of alloy composition where the external oxidation of $B$ is actually prevented by its precipitation as isolated $\mathrm{BO}_{v}$ particles inside the alloy, while $B$ contents exceeding $\mathrm{N}_{\mathrm{B}}{ }^{0 *}(1)$ are already sufficient to form directly external $\mathrm{BO}_{v}$ scales. These general predictions are applied here to the case of oxidation of $\mathrm{Cu}-\mathrm{Al}$ alloys at $1073 \mathrm{~K}$ and compared with the relevant experimental results.

According to a criterion defined by Wagner $/ 10 /$, the transition from internal to external oxidation of $B$ in the high temperature oxidation of binary A-B alloys occurs at a particular $B$ content, $\mathrm{N}_{\mathrm{B}}{ }^{\circ *}(1)$, producing a critical volume fraction of internal oxide, $\mathrm{f}_{\mathrm{v}}{ }^{*}$. In agreement with the results of a detailed study of the oxidation of $\mathrm{Ag}$-In alloys $/ 12,13 /, \mathrm{f}_{\mathrm{v}}{ }^{*}$ is generally set equal to 0.3 . The equations to be used for the calculation of $\mathrm{N}_{B}{ }^{\circ *}(1)$ in the presence of external $\mathrm{AO}$ scales are /13-15/

$$
\mathrm{N}_{\mathrm{O}}{ }^{\mathrm{s}} / \nu \mathrm{N}_{\mathrm{B}}{ }^{\circ}=\mathrm{G}(\gamma)[\operatorname{erf}(\gamma)-\operatorname{erf}(\mathrm{u})] /[\mathrm{F}(\mathrm{h}) \operatorname{erf}(\gamma)]
$$

and

$$
N_{B}{ }^{\circ *}(1)=f_{v}^{*} F(h) / \rho\left(B O_{v}\right)
$$

where $\mathrm{N}_{0}{ }^{\mathrm{s}}$ is the mole fraction of oxygen dissolved in the alloy under the oxygen pressure for the equilibrium between pure $\mathrm{A}$ and $\mathrm{AO}$, while $\gamma$ is a dimensionless parameter related to the parabolic rate constant for internal oxidation according to the equation $\xi^{2}=4 \gamma^{2} D_{0} t$, where $\xi$ is the position of the internal oxidation front measured from the original location of the alloy surface, $D_{0}$ the diffusion coefficient of oxygen in $A$ and $t$ is time. Moreover, $h=\gamma \varphi^{1 / 2}$, with $\varphi=D_{O} / D_{B}$, where $D_{B}$ is the 
diflusion coefficient of $\mathrm{B}$ in the alloy, $\rho\left(\mathrm{BO}_{v}\right)$ is the ratio between the molar volumes of the alloy and $\mathrm{BO}_{v}$ (per mole of metal), while $u$ is equal to $1 / 2\left[k_{c}(A O) / D_{O}\right]^{1 / 2}$ where $k_{c}(A O)$ is the parabolic rate constant for the growth of $\mathrm{AO}$ scales in terms of thickness of metal consumed according to the equation $X^{2}=k_{c}(A O) t$, where $X$ is the thickness of metal consumed by oxidation. Finally, $F(r)$ and $G(r)$ are auxiliary functions defined as $/ 16 /$

$$
G(r)=\pi^{1 / 2} r \exp \left(r^{2}\right) \operatorname{erf}(r)
$$

and

$$
F(r)=\pi^{1 / 2} r \exp \left(r^{2}\right)[1-\operatorname{erf}(r)] .
$$

It is finally noted that the actual thickness of the region of internal oxidation in the presence of an external AO scale does not correspond to $\xi$, but is given by $\xi-\mathrm{X}$.

For alloys undergoing an internal oxidation of $B$ beneath external $\mathrm{AO}$ scales, as observed here for $\mathrm{Cu}$ $1.4 \mathrm{Al}$, it is possible to calculate the appropriate value of $\xi$ after a given oxidation time by solving Eq.(1) using their actual B content. At the same time, the corresponding value of $\mathrm{X}$ may be calculated from the parabolic rate constant expressed in terms of thickness of metal consumed, $k_{c}(A O)$, obtained from the experimental value of the corresponding rate constant expressed in terms of mass gain per unit surface area, $k_{p}(A O)$, by means of an appropriate transformation. Application of this procedure to the results of the oxidation of Cu-1.4Al for $24 \mathrm{~h}$ using the $\mathrm{k}_{\mathrm{p}}$ value reported above yields $\xi=394 \mu \mathrm{m}$ and $X=298 \mu \mathrm{m}$, with $\xi-X=96 \mu \mathrm{m}$ against an experimental value of $\xi-X$ equal to about $110 \mu \mathrm{m}$ (Fig. 2). A better agreement may be obtained by using a modified value of $k_{p}, k_{p}$, which takes into account only the effect due to the growth of the external scales, subtracting from the measured mass gain the contribution due to internal oxidation, calculated from the actual thickness of the zone of internal oxidation measured experimentally. This procedure yields $k_{p}{ }^{\prime}=9.8 \times 10^{-1} \mathrm{~g}^{2} \mathrm{~m}^{-4} \mathrm{~s}^{-1}$, from which the actual thickness of internal oxidation $\xi-X$ is calculated to be equal to $109 \mu \mathrm{m}$, and thus extremely close to the experimental value.

The calculation of $\mathrm{N}_{\mathrm{B}}{ }^{*}(2)$ involves a second criterion, again defined by Wagner $/ 9 /$, which requires that the $\mathrm{B}$ content in the alloy at the interface with the scale during the growth of external $\mathrm{BO}_{v}$ scales does not fall below the value corresponding to the simultaneous equilibrium of the alloy with the oxides of $\mathrm{A}$ and $\mathrm{B}$, $\mathrm{N}_{B}{ }^{\mathrm{cq}}$. This condition involves the solution of the general equation

$$
N_{B}{ }^{o *}(2)=N_{B}{ }^{e q}+\left(1-N_{B}^{e q}\right) F\left(u_{B}\right)
$$

where $u_{B}$ is equal to $1 / 2\left[k_{c}\left(B O_{v}\right) / D_{B}\right]^{1 / 2}$, where $k_{c}\left(B O_{v}\right)$ is the parabolic rate constant for the growth of $\mathrm{BO}_{v}$ in terms of thickness of metal consumed, $Y$, according to the equation $Y^{2}=k_{y} t$. In view of the large difference between the thermodynamic stability of the oxides of $\mathrm{Cu}$ and $\mathrm{Al}, \mathrm{N}_{\mathrm{B}}{ }^{\mathrm{cq}}$ is extremely small and may be neglected, so that Eq.(3a) reduces simply to

$$
N_{B}{ }^{0 *}(2) \approx F\left(u_{B}\right) .
$$

The data required for the evaluation of $\mathrm{N}_{\mathrm{B}}{ }^{0 *}(1)$ and $\mathrm{N}_{\mathrm{B}}{ }^{0 *}(2)$ at $1073 \mathrm{~K}$ are: $\mathrm{D}_{\mathrm{N1}}=3 \times 10^{-14} \mathrm{~m}^{2} \mathrm{~s}^{-1} / 17 /, \mathrm{D}_{\mathrm{O}}=$ $6.12 \times 10^{-10} \mathrm{~m}^{2} \mathrm{~s}^{-1} / 18 /$ and $\mathrm{N}_{\mathrm{o}}^{\mathrm{s}}=7.98 \times 10^{-6} / 18 /$, while the parabolic rate constant for the growth of copper oxide, $\mathrm{k}_{\mathrm{c}}\left(\mathrm{CuO}_{\mathrm{x}}\right)$, is set equal to $4.3 \times 10^{-13} \mathrm{~m}^{2} \mathrm{~s}^{-1} / 19 /$. Finally, the rate constant for the growth of alumina scales calculated from data about the oxidation of $\mathrm{Al}$-rich $\mathrm{Fe}-\mathrm{Al}$ alloys is equal to $4.4 \times 10^{-20} \mathrm{~m}^{2} \mathrm{~s}^{-1}\left[\mathrm{k}_{\mathrm{c}}\left(\mathrm{Al}_{2} \mathrm{O}_{3}\right)(1)\right] / 20 \%$, while that measured here for $\mathrm{Cu}-4.2 \mathrm{Al}$ and $\mathrm{Cu}-6.5 \mathrm{Al}$ is equal to $4.8 \times 10^{18} \mathrm{~m}^{2} \mathrm{~s}^{-1}\left[\mathrm{k}_{\mathrm{c}}\left(\mathrm{Al}_{2} \mathrm{O}_{3}\right)(2)\right]$. Introduction of .these parameters into the relevant equations yields $\mathrm{N}_{N}{ }^{0 *}{ }^{*}(1)=$ 0.152 , while $\mathrm{N}_{N}{ }^{0 *}(2)$ becomes equal to $1.1 \times 10^{-3}$ using $\mathrm{k}_{\mathrm{c}}\left(\mathrm{Al}_{2} \mathrm{O}_{3}\right)(1)$ or to $=1.1 \times 10^{-2}$ using $\mathrm{k}_{\mathrm{c}}\left(\mathrm{Al}_{2} \mathrm{O}_{3}\right)(2)$, against estimated experimental values of about 2.5 at. $\%$ and 4 at. $\%$ for $N_{N I}{ }^{0}{ }^{*}(1)$ and $N_{\Lambda l}{ }^{0}{ }^{*}(2)$, respectively.

Both the calculated values are in significant disagreement with the corresponding experimental values. In particular, the experimental results show the existence of two transitions, while the calculated values of $N_{\Lambda^{\prime}}{ }^{\circ *}(1)$ and $N_{N}{ }^{\circ *}(2)$ predict only a single transition (transition 1-3). Possible reasons for this discrepancy for $\mathrm{N}_{\mathrm{NI}}{ }^{{ }^{*}}(1)$ are: a) the actual value of $\mathrm{f}_{\mathrm{v}}{ }^{*}$ for $\mathrm{Cu}-\mathrm{Al}$ alloys may differ from the classical value of 0.3 , determined for the oxidation of Ag-In alloys $/ 11 /$, especially in view of the anomalous nature of the internal oxidation in alloys not too dilute in aluminum, as observed here for 
$\mathrm{Cu}-2 \mathrm{Al}$ and b) the uncertainty in the values of some of the parameters used, such as $\mathrm{D}_{\mathrm{Al}}$, as already pointed out elsewhere $/ 8 /$. For $\mathrm{N}_{\mathrm{NI}}{ }^{*}(2)$, it is possible that the critical content given by Eq.(3b) may represent only a necessary but not a sufficient condition for the growth of external $\mathrm{Al}_{2} \mathrm{O}_{3}$ scales, as already noted by Wagner 19/. This is especially likely in view of the very low rate of growth of external $\mathrm{Al}_{2} \mathrm{O}_{3}$ scales, which could prevent the formation of a continuous layer of this oxide at the base of the scale below a sufficient $\mathrm{Al}$ level in the alloy, which appears to be much larger than the value calculated for $\mathrm{N}_{\Lambda 1}{ }^{\circ}$ (2).

\section{CONCLUSIONS}

The addition of aluminum to copper produces first a transition from its internal oxidation to the formation of external scales composed of mixtures of copper and aluminum oxides and later on a transition from the formation of mixed external scales to the growth of continuous protective $\mathrm{Al}_{2} \mathrm{O}_{3}$ layers directly in contact with the alloy. The experimental values of the critical $\mathrm{Al}$ contents required for these two transitions, amounting to about 2.5 at.\% and 4 at.\%, respectively, differ quite significantly from the corresponding calculated values, which, moreover, predict only the existence of a direct transition from internal to external oxidation of aluminum. The discrepancies between calculated and experimental values of the two critical $\mathrm{Al}$ contents are attributed both to limitations of the theory and to uncertainties in the values of the parameters used for the calculations.

\section{ACKNOWLEDGEMENTS}

Financial support by the National Natural Scientific Foundation of China (NSFC) under Grant 50571107 is gratefully acknowledged.

\section{REFERENCES}

I. J.S.Dunn, J. Inst. Met, 46,25 (1934).

2. K.W. Frohlich, Zeit Metallkde, 28,368 (1936).

3. L.E. Price, G.J. Thomas, J. Inst. Met, 63, 21 (1936).

4. J.P. Dennison, A. Preece, J. Inst. Met, 81,229 (1952).

5. J.C. Blade, A. Preece, J. Inst. Met, 88,427 (1952).

6. C. Wagner, Corros. Sci, 5, 751 (1965).

7. M.D. Sanderson, J.C. Scully, Oxid. Met, 3, 59 (1971).

8. S.Y. Wang, F. Gesmundo, W.T. Wu, Y. Niu, Scripta Materialia, 54,1563 (2006).

9. C. Wagner, J. Electrochem. Soc, 99,369 (1952).

10. C. Wagner, Zeit Elektrochem, 63,772 (1959).

11. F. Gesmundo, Y. Niu, Oxid. Met, 50,1 (1998).

12. R.A. Rapp, Acta Metall, 9,730 (1961).

13. R.A. Rapp, Corrosion, 21,382 (1965).

14. F. Maak, Zeit Metallkde, 52,545 (1961).

15. F. Gesmundo, F. Viani, Oxid. Met, 25,269 (1986).

16. J. Crank, The Mathematics of Diffusion, Oxford University Press, New York, 1994

17. F.N. Rhines, R.F. Mehl, Trans. AIME, 128,185 (1938).

18. M.L. Narula, V.B. Tare, W.L. Worrell, Metall. Trans, 14B, 673 (1983).

19. Y. Niu, F. Gesmundo, D.L. Douglass, F. Viani, Oxid. Met, 48,357 (1997).

20. W.C. Hagel, Corrosion, 21,316 (1965). 